\title{
Naturally occurring mastitis effects on timing of ovulation, steroid and gonadotrophic hormone concentrations, and follicular and luteal growth in cows
}

\author{
Y. Lavon, ${ }^{*}$ G. Leitner,† H. Voet, $\ddagger$ and D. Wolfenson*1 \\ *Department of Animal Science, Faculty of Agriculture, Food and Environment, the Hebrew University, Rehovot, 76100 Israel \\ †Mastitis Laboratory, The Veterinary Institute, Bet Dagan, 50250, Israel \\ ‡Department of Agricultural Economics and Management, Faculty of Agriculture, Food and Environment, the Hebrew University, Rehovot, \\ 76100 Israel
}

\section{ABSTRACT}

The effects of naturally occurring subclinical chronic or clinical short-term mastitis on time of ovulation, plasma steroid and gonadotropin concentrations, and follicular and luteal dynamics were examined in 73 lactating Holstein cows. Cows were sorted by milk somatic cell count and bacteriological examination into an uninfected group $(\mathrm{n}=22)$, a clinical mastitis group $(\mathrm{n}=$ 9; events occurring $20 \pm 7 \mathrm{~d}$ before the study), and a subclinical chronic mastitis group $(\mathrm{n}=42)$. In addition, uninfected and mastitic cows were further sorted by their estrus to ovulation (E-O) interval. About 30\% of mastitic cows (mainly subclinical) manifested an extended E-O interval of $56 \pm 9.2 \mathrm{~h}$ compared with 28 $\pm 0.8 \mathrm{~h}$ in uninfected cows and $29 \pm 0.5 \mathrm{~h}$ in the other $70 \%$ of mastitic cows. In mastitic cows with extended E-O interval, the concentration of plasma estradiol at onset of estrus was lower than that of uninfected cows or mastitic cows that exhibited normal E-O intervals $(3.1 \pm 0.4,5.8 \pm 0.5$, and $5.5 \pm 0.5 \mathrm{pg} / \mathrm{mL}$, respectively). The disruptive effect of mastitis on follicular estradiol probably does not involve alterations in gonadotropin secretion because any depressive effects of mastitis on pulsatile LH concentrations were not detected. Cortisol concentrations did not differ among groups. The preovulatory LH surge in mastitic cows with delayed ovulation varied among individuals, being lower, delayed, or with no surge noted compared with the normal LH surge exhibited by uninfected cows or mastitic cows with normal E-O interval $(6.8 \pm 0.7 \mathrm{ng} /$ $\mathrm{mL}$ ). The diameter of the second-wave dominant follicle was larger and the number of medium follicles was smaller in uninfected and subclinical cows with normal intervals compared with subclinical cows with extended

Received February 8, 2009.

Accepted November 23, 2009.

${ }^{1}$ Corresponding author: wolf@agri.huji.ac.il intervals $(13.4 \pm 0.5$ vs. $10.9 \pm 0.9 \mathrm{~mm}$, and $3.8 \pm$ 0.2 vs. $6.7 \pm 0.14$ follicles, respectively). Mid-luteal progesterone concentrations were similar in uninfected and mastitic cows. These results indicate for the first time that around $30 \%$ of cows with subclinical chronic mastitis exhibit delayed ovulation that is associated with low plasma concentrations of estradiol and a low or delayed preovulatory LH surge.

Key words: mastitis, ovulation, hormone, dairy cow

\section{INTRODUCTION}

Mastitis, clinical or subclinical, is the most common disease affecting dairy cattle worldwide. Mastitis not only affects milk production and quality but also depresses fertility of dairy cows, causing significant losses to the dairy industry. A series of epidemiological studies performed in the past decade indicated that mastitis had a negative effect on the reproductive performance of dairy cows (Schrick et al., 2001; Santos et al., 2004). Recent studies found that mastitis was genetically associated with reduced fertility, with a genetic correlation ranging between 0.21 and 0.41 (Heringstad et al., 2006). Yet, the specific effects on conception are controversial, particularly with regard to the timing of mastitis occurring either before or after AI, whether it is clinical or subclinical mastitis, and regarding the IMI-causing pathogens, gram-positive or gram-negative bacteria.

There is general agreement that clinical mastitis after AI is strongly associated with low conception and higher services per conception (Konig et al., 2006), regardless of whether the IMI-induced bacteria are grampositive or gram-negative (Schrick et al., 2001; Santos et al., 2004). In contrast, the effect of IMI before AI on reproduction is controversial. Some researchers claim that there is no effect on conception rates or days open (Klaas et al., 2004). Others claim that high SCC before AI has some effect on the nonreturn rate, which does not warrant the postponing of first-service AI (Miller et al., 2001). In contrast, Schrick et al. (2001) pointed 
out that cows with either clinical or subclinical mastitis before first AI had increased days open and services per conception and that reproductive performance did not differ between types of pathogens. In agreement, Santos et al. (2004) showed that first AI conception rates were depressed by clinical mastitis occurring before AI, caused by either gram-positive or gram-negative bacteria. Konig et al. (2006) found that SCC >400,000 cells/mL of milk during the entire lactation (probably chronic subclinical mastitis) lowered the pregnancy rate. Despite the equivocal findings, the above epidemiological studies indicate that 1) subclinical mastitis is associated with decreased reproductive performance, 2) mastitis before AI lowers the conception rate, and 3) gram-positive toxin disrupts fertility, similar to gramnegative endotoxin.

The possible mechanisms by which mastitis negatively affects reproduction are unclear. Regarding IMI before ovulation, several studies found that induced clinical mastitis during the follicular phase reduced pulsatile LH secretion, causing low estradiol concentrations and delayed LH surge and ovulation (Hockett et al., 2005; Lavon et al., 2008a). Common to the abovementioned studies is the induction of acute, short-term, experimental pathogenic stress models in the form of intramammary administration of either bacteria or endotoxin (mainly of Escherichia coli origin). The abovementioned studies do not simulate subclinical, chronic, long-term mastitis cases that last several months, or a possible carryover effect on reproductive responses of clinical events that ended several weeks earlier.

Gram-positive bacteria are capable of disrupting reproductive functions. For example, mammary inoculation with gram-positive bacteria (Streptococcus uberis) depressed estrous behavior and altered hormonal concentrations in cows, including decreased preovulatory estradiol and LH concentrations (Hockett et al., 2000, 2005). Recently, intramammary infusion of peptidoglycan induced a carryover effect on follicular androgen and estrogen concentrations in cows (Lavon et al., 2009b). Collectively, these studies suggest that grampositive toxin was associated with reproductive failure, similar to gram-negative endotoxin.

Studies investigating a possible link between mastitis occurring post-ovulation and AI and early regression of the corpus luteum (CL) have not been as conclusive. Hockett et al. (2000), showing elevated $\mathrm{PGF}_{2 \alpha}$ metabolite level in induced-mastitis cows, speculated on prostaglandin's role in early luteal regression; Huszenicza et al. (2005) found a higher proportion of short luteal phases in cows exhibiting clinical mastitis during the luteal phase; and Giri et al. (1991) reported that endotoxin induced an increase of circulating $\mathrm{PGF}_{2 \alpha}$ and a subsequent decrease in progesterone concentrations.
The objective of this study was to examine the effects of naturally occurring subclinical chronic IMI, or shortterm clinical IMI events that occurred before the study on reproductive responses, including timing of ovulation relative to onset of estrus. Based on the above, uninfected and mastitic cows were divided into those exhibiting normal or extended estrus to ovulation (EO) interval, and the following endocrine responses were assessed: LH pulsatility before estrus and preovulatory LH surge concentrations, ovarian follicular and luteal characteristics, and plasma steroid concentrations. To the best of our knowledge, the effects of naturally occurring IMI, as described above, have not been previously examined.

\section{MATERIALS AND METHODS}

\section{Animals}

The experiment was carried out on 73 cyclic Holstein cows in their first to fifth lactation; the cows manifested estrus during the experimental period described below. The cows were kept in an open shed and had access to an adjacent yard. They were fed a TMR containing $16.8 \% \mathrm{CP}$ and $1.75 \mathrm{Mcal} / \mathrm{kg}$ of DM. The experiment was conducted during the comfortable months of the year, when minimal and maximal air temperature and relative humidity were 12.6 and $23.1^{\circ} \mathrm{C}$ and 43 and $88 \%$, respectively. Prior to the experiment, cows were monitored 2 or 3 times by analyzing the monthly routine test-day milk samples for SCC (Fossomatic 360 instrument, Foss Electric, Hillerød, Denmark). In addition, 3 sequential aseptic milk samples that were taken weekly from each of the 4 quarters before starting the experiment were analyzed for SCC as well as for bacteriological determination. The SCC of each quarter was determined with a Coulter cell counter (Z1 Coulter Electronics, Luton, UK) as described previously (Younis et al., 2003).

The experiment was designed with 6 clusters of cows before first AI that were grouped according to their calving dates. Each cluster of cows $(\mathrm{n}=8-16)$ comprised, as described below, all eligible clinical or subclinical mastitic cows $(n=6-11)$ and uninfected control cows. Cows were divided into 3 groups according to the level of SCC and the bacteriological data taken before starting the experiment. The uninfected group ( $\mathrm{n}=$ 22) consisted of cows with no udder infection and with SCC $<200,000 / \mathrm{mL}$ of milk in all the monthly test-day samples as well as the quarter milk samples collected before the experiment. The actual SCC of uninfected cows was $64 \pm 7\left(\times 10^{3}\right)$ cells $/ \mathrm{mL}$ of milk. The clinical group $(\mathrm{n}=9)$ consisted of cows that had exhibited a clinical mastitis event $20 \pm 7 \mathrm{~d}(\mathrm{SE}$, range $=12-43 \mathrm{~d})$ 
before the study. Clinical mastitis events were identified and recorded by experienced milking personnel according to the abnormalities of the milk and typical udder swelling. Once a clinical event was recorded, a single aseptic milk sample was collected to identify the bacteria involved and to monitor SCC (the actual SCC value was $3,204 \pm 610 \times 10^{3}$ cells $/ \mathrm{mL}$ of milk). Clinical mastitic cows maintained high SCC for a few days, which later decreased to $451 \pm 235 \times 10^{3}$ cells $/ \mathrm{mL}$ of milk, with no bacteria found close to the start of the experiment. The subclinical group $(\mathrm{n}=42)$ manifested a typical long-term, chronic disease. For more than 60 $\mathrm{d}$, in all the routine monthly samples and the quarter samples, the subclinical cows had SCC $>250,000$ cells/ $\mathrm{mL}$ of milk and were IMI in at least 1 quarter by various bacteria, before and close to the experiment. The SCC for subclinical cows was $782 \pm 153 \times 10^{3}$ cells $/ \mathrm{mL}$ of milk. Each of the 3 experimental groups were further sorted to cows exhibiting a normal or extended E-O interval, as will be later described. The experiment was approved by the local ethics committee of the Hebrew University (Rehovot, Israel).

\section{Milk Samples}

Before samples were taken, the teats were immersed in an iodine solution and dried thoroughly with paper towels, after which they were sanitized with swabs containing $70 \%$ isopropyl alcohol. Bacteriological analysis was performed according to accepted standards (Oliver et al., 2004). From every milk sample, $0.01 \mathrm{~mL}$ was spread onto blood-agar plates (Bacto-Agar, Difco Laboratory, Becton, Dickinson \& Co., le-Pontde-Claix, France) containing $5 \%$ of washed sheep red blood cells and on MacConkey plates. All plates were incubated at $37^{\circ} \mathrm{C}$ and examined for growth after 18 and $42 \mathrm{~h}$. Colonies suspected to be staphylococci were tested for coagulase (tube test; Anilab, Rehovot, Israel). Strain identification was carried out with the API StaphIdent, 32 Staph kit, or rapid ID 32 Strep (BioMerieux S.A., Marcy-l'Etoile, France). When the percentage of micrococci-like bacteria that matched the test strain exceeded 90\%, the strain was regarded as specific. Gram-negative colonies were identified by API $20 \mathrm{E}$ or API NE (BioMerieux S.A.).

\section{Experimental Protocol}

Estrus cycles were synchronized by 2 doses of $\mathrm{PGF}_{2 \alpha}$ analog (500 mg of Cloprostenol, Estroplan, Parnell Laboratories, Alexandria, Australia) given intramuscularly $13 \mathrm{~d}$ apart. For a 4 -d period, starting about $40 \mathrm{~h}$ after the second $\mathrm{PGF}_{2 \alpha}$ injection, cows were checked for estrus every $4 \mathrm{~h}$, each time for $45 \mathrm{~min}$. In addition, estrus was detected 3 times daily during milking by a computerized pedometric system (Afimilk, Afikim, Israel). Taken together, onset of estrus was recorded with an estimated accuracy of $\pm 2 \mathrm{~h}$. Cows $(23 / 96)$ that underwent the synchronization procedure and did not manifest estrus within the 4-d period were excluded from the study. During synchronization, ultrasonographic scanning (7.5-MHz linear probe with SSD-900 Aloka instrument, Tokyo, Japan) was used to confirm the normal appearance of structures in the ovaries. Structures typical for cyclic cows were recorded at the first $\mathrm{PGF}_{2 \alpha}$ injection, and the appearance of structures typical for the time before induction of a follicular phase were recorded at the second $\mathrm{PGF}_{2 \alpha}$ injection (functional CL and large follicle). All experimental cows manifested normal appearance of ovarian structures.

Blood samples were collected into heparinized tubes from randomly selected subgroups of healthy $(\mathrm{n}=11)$, clinical $(\mathrm{n}=8)$, and subclinical $(\mathrm{n}=20)$ cows for determining estradiol and LH surge at the onset of estrus and every $4 \mathrm{~h}$ until ovulation was confirmed, or until $96 \mathrm{~h}$ after estrus onset from cows that failed to ovulate. Following ovulation, samples were taken every $3 \mathrm{~d}$ throughout the cycle for determining progesterone and cortisol. In addition, frequent blood samples were collected from a subgroup of cows ( 5 healthy, 6 subclinical, and 5 clinical mastitic) that were eligible during the same time period to examine pulsatile LH secretion. For this procedure, the jugular veins were catheterized approximately $24 \mathrm{~h}$ after the second $\mathrm{PGF}_{2 \alpha}$ injection, and $12 \mathrm{~h}$ later ( $36 \mathrm{~h}$ after the second $\mathrm{PGF}_{2 \alpha}$ injection), blood samples were collected at 15-min intervals for 6 h. Plasma samples were stored at $-20^{\circ} \mathrm{C}$ until assayed. To determine the time of ovulation, ultrasonography was carried out in all cows twice daily at 12-h intervals from about $20 \mathrm{~h}$ after onset of estrus until ovulation was confirmed, or until $96 \mathrm{~h}$ after onset of estrus in cows that failed to ovulate at that time. Following ovulation, scanning of the ovaries was carried out every 2 to $3 \mathrm{~d}$ to characterize follicular growth dynamics and CL development.

\section{Hormonal Analyses}

Estradiol was measured in extracted plasma samples using an RIA kit (DSL-4800, Diagnostic System Laboratory, Webster, TX). The standard curve was made in charcoal-stripped bovine plasma (Turzillo and Fortune, 1990). Cross-reactivity of the assay was $2.4 \%$ for estrone and $0.4 \%$ for estriol. The minimal detectable amount was $0.5 \mathrm{pg} / \mathrm{mL}$, and the intra- and interassay coefficients of variation were 3 and $5 \%$, respectively. Plasma progesterone concentrations were analyzed with a solid-phase RIA kit (Diagnostic Product Corp., 
Los Angeles, CA) against a standard curve prepared in ovariectomized cow plasma (Shaham-Albalancy et al., 2000). The minimal detectable amount was $0.2 \mathrm{ng} / \mathrm{mL}$, and the intra- and interassay coefficients of variations were 8.6 and $9.9 \%$, respectively. Plasma cortisol concentrations were analyzed with a solid-phase RIA kit (Diagnostic Product Corp.) against a given standard curve with 2 more concentrations. These were prepared by diluting the original standards $(5-500 \mathrm{ng} / \mathrm{mL}$ range of the standard curve). The minimal detectable amount was $2 \mathrm{ng} / \mathrm{mL}$, and the intra- and interassay coefficients of variations were 4.2 and $5.2 \%$, respectively. Plasma LH concentrations were measured by an enzyme immunoassay kit (LH Detect, Reprokit, Sanofi Sante Animale, Libourne, France) against a given standard curve (range $=0.06-4 \mathrm{ng} / \mathrm{mL}$ ). The assay was described previously and validated (Lavon et al., 2008a). The minimal detectable amount was $0.1 \mathrm{ng} / \mathrm{mL}$, and the intra- and interassay coefficients of variations were 3.4 and $6.8 \%$, respectively.

\section{Data Analyses}

Cows were classified within each experimental group (uninfected, clinical, or subclinical) as exhibiting a normal or an extended E-O interval. For defining the E-O interval as normal or extended, we used a threshold of $36 \mathrm{~h}$ based on our own experience (Bloch et al., 2006) and that of others (Roelofs et al., 2005). The entire study group (with the exception of missing data) was used to analyze the risk factors affecting E-O interval. The chi-squared or Fisher exact test (as applicable) was used for univariate examination of the association between extended E-O interval and mastitis type and between extended E-O interval and possible risk factors including parity, milk production, DIM, BCS, and postpartum uterine diseases (metritis, endometritis, and retained fetal membranes). Backward stepwise logistic regression (with significance-to-stay of 0.1 ) was used to examine the simultaneous effect of mastitis type and risk factors on extended E-O interval.

For the analyses of hormone concentrations and follicular and luteal dynamics, subsets of the study groups were used as detailed above. The MIXED procedure of SAS (SAS Institute, Cary, NC) was used for the repeated measures analysis (with autoregressive covariance structure). Normality was established by examination of the residuals. For progesterone, follicle size, and follicle numbers, logarithmic and square root transformations were used to normalize data and stabilize variances. The statistical model included experimental group (fixed effect; uninfected, clinical mastitis with normal or extended E-O interval, subclinical mastitis with normal or extended E-O interval), cows within groups (random effect), time (fixed effect; hours or days), and the interaction of time with group. Data sets that consisted of 1 piece of data per cow, such as length of E-O interval, peak estradiol concentrations at estrus, mean cortisol concentrations, or peak LH surge and its interval from onset of estrus, were tested with 1-way ANOVA. The Tukey-Kramer test was used for pairwise comparisons of groups. The frequencies of LH pulses were identified using the Cluster pulse-detection algorithm (PcPulsar; Veldhuis and Johnson, 1986). The LH pulse amplitudes were defined and calculated according to the difference between the peak and its preceding nadir. Mean LH was the average of LH values during the $6 \mathrm{~h}$ of sampling. Ultrasound measurements of follicles and CL were used to calculate the average diameter and volume (V). The volume of the CL was calculated according to the formula $\mathrm{V}=4 / 3 \pi \mathrm{R}^{3}$, using a radius $(\mathrm{R})$ calculated by the formula $\mathrm{R}=(\mathrm{L} / 2+$ $\mathrm{W} / 2) / 2$, where $\mathrm{L}$ is length and $\mathrm{W}$ is width. For a CL with a fluid-filled cavity, the volume of the cavity was calculated and subtracted from the total volume of the CL. Data are presented as means and SEM. Probability values $\leq 0.05$ were considered significant, whereas 0.05 $<P \leq 0.10$ was considered a tendency.

\section{RESULTS}

\section{Mastitis Effect on E-O Interval}

Of the 73 experimental cows, 5 subclinical cows contributed to the data sets of hormone concentrations and follicular dynamics, but they did not contribute E-O interval data because of incomplete information regarding timing records of onset of estrus or ovulation. None of the following risk factors differed among uninfected, subclinical, and clinical mastitic groups: milk yield $(41.7 \pm 1.6,39.2 \pm 1.4$, and $38.1 \pm 2.6 \mathrm{~kg} / \mathrm{d}$, respectively), BCS $(2.9 \pm 0.1,2.8 \pm 0.1$, and $2.8 \pm 0.1$, respectively, on a $1-5$ scale), and DIM $(87 \pm 6,100 \pm$ 5 , and $101 \pm 12 \mathrm{~d}$, respectively). Distribution of cows to young (first and second lactation) and mature (third to fifth lactation) subgroups were 67 and $33 \%, 62$ and $38 \%$, and 67 and $33 \%$, respectively. Postpartum uterine diseases (pool of metritis, endometritis, and retained fetal membranes) were 27,27 , and $22 \%$, respectively. Furthermore, none of the above provided any significant explanation for the extended E-O interval. In backward stepwise logistic regression (significance-tostay $=0.1$ ) for the subclinical mastitis group or for the combination of both mastitis types into a single group, none of the above-mentioned risk factors were retained (the significance of mastitis type was 0.064 and 0.072 , respectively). Consequently, the association between mastitis type and extended E-O interval was analyzed at a univariate level. 

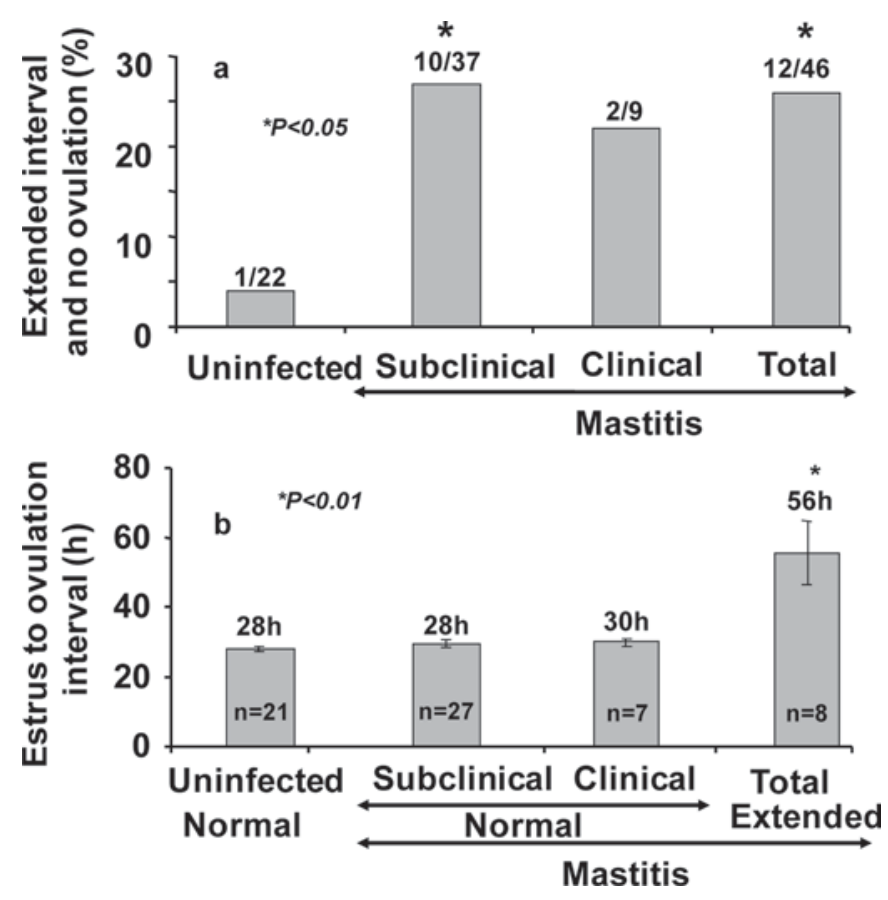

Figure 1. Estrus to ovulation (E-O) intervals in uninfected cows $(\mathrm{n}=22)$ and in cows with clinical $(\mathrm{n}=9)$ or subclinical $(\mathrm{n}=37)$ mastitis. a) Percentage of cows exhibiting an extended E-O interval and cows that did not ovulate during the 96-h experimental period after onset of estrus. An asterisk indicates the difference between uninfected cows and subclinical or total mastitic cows that exhibited an extended E-O interval or those that did not ovulate $(P<0.05)$. b) The E-O interval in uninfected cows exhibiting a normal interval and in clinical or subclinical mastitic cows exhibiting a normal or extended interval. One uninfected cow with extended E-O interval (76 DIM; fourth lactation; $54 \mathrm{~kg}$ of milk/d; SCC $43 \times 10^{3}$ cells $/ \mathrm{mL}$ ) that had postpartum disease was not included. Four of 12 cows did not ovulate during the experimental period. An asterisk indicates the difference in E-O interval between mastitic cows exhibiting an extended interval and uninfected or mastitic cows exhibiting a normal interval $(P<0.01)$.

The percentages of healthy cows compared with clinical and subclinical mastitic cows that exhibited a normal or long E-O interval are presented in Figure 1a. A total of 12 out of $46(26 \%)$ grouped subclinical and clinical mastitic cows exhibited an E-O interval that was longer than normal $(\mathrm{n}=8)$ or did not ovulate during the $96-\mathrm{h}$ experimental period $(\mathrm{n}=4)$. This proportion differed from that in the uninfected group, in which only 1 cow out of 22 ( 4 vs. $26 \% ; P<0.05$ ) manifested delayed ovulation. The subclinical mastitic group differed from the uninfected group $(27 \%, 10 / 37$ cows; $P<0.05$ ), but the smaller clinical group did not (22\%, 2/9 cows). The 2 clinical mastitic cows exhibiting an extended E-O interval manifested a clinical mastitic event a long $(43 \mathrm{~d})$ or short $(14 \mathrm{~d})$ time before the experiment. Of the 4 out of 12 abnormal cows that did not ovulate during the 96 -h experimental period, 1 was clinical and the other 3 were subclinical. The majority $(74 \%)$ of mastitic cows exhibited normal E-O intervals.
The duration of their E-O intervals $(28.9 \pm 0.5 \mathrm{~h}$; Figure 1b) was similar to that in uninfected normal cows $(28.2 \pm 0.8 \mathrm{~h})$, and both differed from subclinical and clinical mastitic cows with extended E-O intervals $(55.6$ $\pm 9.2 \mathrm{~h} ; P<0.01)$.

Note that all mastitic cows (clinical and subclinical), including those exhibiting an extended E-O interval and cows that did not ovulate during the 96-h experimental period after onset of estrus, had ovarian structures that manifested a normal appearance during the synchronization procedure before estrus, with no indications of the presence of either cysts or persistent follicles. At the time of the second $\mathrm{PGF}_{2 \alpha}$ injection, the following were recorded: 1 ) a new CL developed (volume range = $\left.6,120-9,950 \mathrm{~mm}^{3}\right) ; 2$ ) the large follicle (diameter range $=13.8-15.7 \mathrm{~mm}$ ) developed in a location different from that of the large follicle detected during the first $\mathrm{PGF}_{2 \alpha}$ injection; and 3) the number of large follicles presented ranged from 1.08 to 1.25. All were indications of a normal follicular wave turnover that did not differ between the experimental groups. Additionally, all groups of cows exhibited estrus in a similar interval from the time of the second $\mathrm{PGF}_{2 \alpha}$ injection (range $=2.9-3.2 \mathrm{~d}$ ).

\section{Bacterial Analysis}

Mastitis pathogens isolated from mammary glands of the infected cows are in Table 1. Data were split between groups exhibiting normal or extended E-O interval. The majority of the clinical infections were caused by E. coli, whereas the subclinical infections were caused by Streptococcus dysgalactiae and coagulase-negative staphylococci. No relationship was found between type of bacteria, gram-positive or gram-negative, and disruption of reproductive function. Among the subclinical cows, the SCC did not differ between cows with normal or extended E-O interval.

\section{Hormone Concentrations Before and After Ovulation}

Cortisol concentrations were similar in the 3 samples collected around estrus. Mean values that ranged from 8 to $11 \mathrm{ng} / \mathrm{mL}$ did not differ among healthy, clinical, or subclinical mastitic cows exhibiting either normal or delayed ovulation (Figure 2). Estradiol concentrations at onset of estrus (about $6 \mathrm{pg} / \mathrm{mL}$ ) did not differ among cows exhibiting normal E-O intervals of either healthy, clinical, or subclinical mastitic cows (Figure 3). In contrast, clinical or subclinical mastitic cows with an extended E-O interval exhibited lower concentrations of $3 \pm 0.4 \mathrm{pg} / \mathrm{mL}(P<0.01)$.

Three representative individual profiles of pulsatile LH concentration during the follicular phase before estrus of healthy, clinical, and subclinical mastitic cows 
Table 1. Mastitis pathogens isolated from mammary glands of cows with clinical or subclinical mastitis exhibiting normal or delayed ovulation

\begin{tabular}{lcccccr}
\hline & \multicolumn{2}{c}{ Clinical mastitis } & & \multicolumn{2}{c}{ Subclinical mastitis } & \\
\cline { 2 - 3 } Pathogen & \multirow{2}{*}{ Normal } & Delayed & & Normal & Delayed & Total \\
\hline Streptococcus nonagalactiae & & & & 13 & 4 & 17 \\
Coliform & 6 & 1 & & 2 & & 9 \\
CNS & 1 & & & & 6 & 21 \\
Pasteurella & & & & & & 1 \\
Staphylococcus aureus & & 1 & & & & 1 \\
No bacterial growth & & & & & & \\
\hline
\end{tabular}

are in Figure 4. Means and amplitude LH concentrations did not differ among the 3 groups (Table 2). Two of the 6 subclinical cows that later exhibited an extended E-O interval manifested pulsatile LH concentrations similar to those of their 4 other subclinical counterparts exhibiting normal E-O interval. The frequency of LH pulses was, as expected for the follicular phase in cattle, around 1 pulse/h for the 3 groups (Table 2).

Mean peak concentrations of LH surges as well as the time that they occurred after onset of estrus did not differ among healthy, clinical, or subclinical mastitic cows exhibiting a normal E-O interval $(6.8 \pm 0.7 \mathrm{ng} /$ $\mathrm{mL}$ and $4.6 \pm 0.8 \mathrm{~h}$ after onset of estrus; Figure $5 \mathrm{a}$ ). In contrast, cows with clinical or subclinical mastitis that exhibited an extended E-O interval displayed variable profiles in terms of both LH surge concentration and the timing of its appearance (Figures $5 \mathrm{~b}, 5 \mathrm{c}$ ). Of the 12 mastitic cows with an extended E-O interval, 7 cows were sampled for LH surge. Of these, 3 cows manifested a low peak surge $(2.1-3.6 \mathrm{ng} / \mathrm{mL})$ ranging from 4 to 21

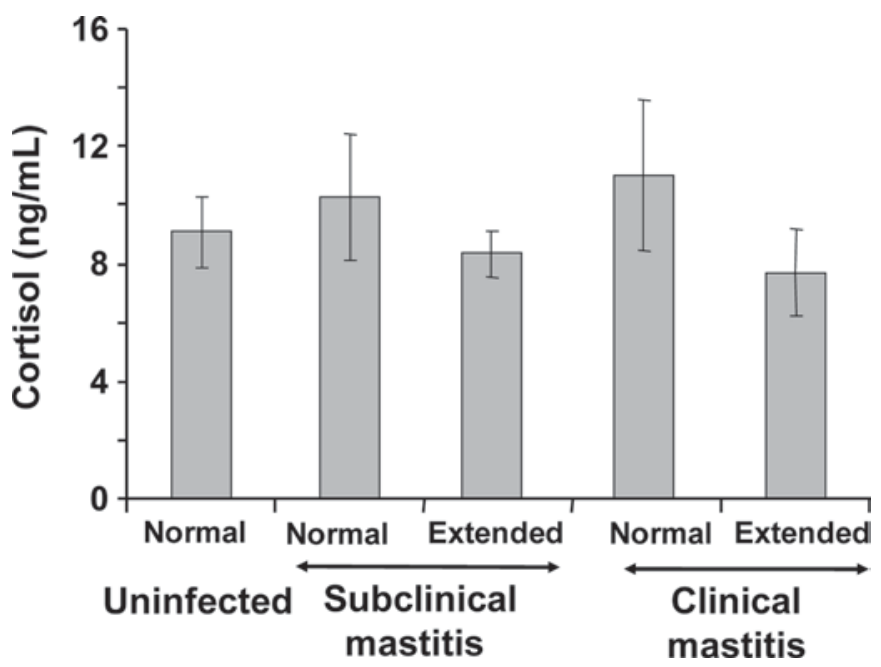

Figure 2. Mean $( \pm \mathrm{SE})$ concentrations of cortisol in plasma from 3 representative days around estrus $(\mathrm{d} 19,0$, and 1$)$ in uninfected cows $(\mathrm{n}=9)$ exhibiting a normal estrus to ovulation (E-O) interval and in subclinical or clinical mastitic cows exhibiting normal $(\mathrm{n}=14$ or 5 , respectively) or extended ( $\mathrm{n}=5$ or 2 , respectively) E-O intervals. $\mathrm{h}$ after onset of estrus (Figure $5 \mathrm{~b}$ ). Two other cows that had delayed LH surge (9-19 h after estrus; Figure 5c) exhibited peaks of 9.5 to $13.5 \mathrm{ng} / \mathrm{mL}$. Of the 2 out of 7 cows that did not ovulate during the 96-h experimental period, one exhibited a low LH level of $1.2 \pm 0.04 \mathrm{ng} /$ $\mathrm{mL}$ and the other exhibited a low LH surge concentration $(2 \mathrm{ng} / \mathrm{mL})$ that was not high enough to induce ovulation (Figure 5d). Collectively, 5 out of the 7 cows exhibited an LH surge that was lower than that in the normal cows described previously $(P<0.01$, Fisher's exact test; $5 / 7$ mastitic cows with low LH surge and delayed ovulation vs. 0/10 of their uninfected counterparts). The interval between estrus onset to LH surge of those cows exhibiting delayed ovulation was longer than that of the normal cows described previously (10.5 \pm 1.7 vs. $4.6 \pm 0.8 \mathrm{~h} ; P<0.01)$. Similar to the E-O interval presented in Figure 1, the LH surge to ovulation intervals of uninfected normal, subclinical normal, clinical normal, and mastitic cows with an extended E-O interval were, respectively, $24.4 \pm 0.7,25.8 \pm 1.4$, $25.5 \pm 1.2$, and $53.0 \pm 13.6 \mathrm{~h}$; the latter differed from the first $3(P<0.05)$.

Following ovulation, plasma concentrations of progesterone did not differ significantly at mid-luteal phase between healthy, clinical, and subclinical mastitic cows with a normal interval, and subclinical mastitis cows with delayed ovulation (Figure 6a). The mean CL volume did not differ among treatment groups (Figure $6 b)$.

The 4 abnormal cows that did not ovulate during the 96-h period following onset of estrus later had a turnover of the preovulatory follicles. In all cows, a new dominant follicle developed. Of these, in 3 cows ovulation and the formation of new CL were evident, and in 1 cow the new dominant follicle did not ovulate throughout the cycle.

\section{Follicular and Luteal Dynamics After Ovulation}

The duration of the estrus cycle post-ovulation did not differ significantly among groups exhibiting normal or delayed ovulation $($ range $=22-23 \mathrm{~d}$ ). The mean size 


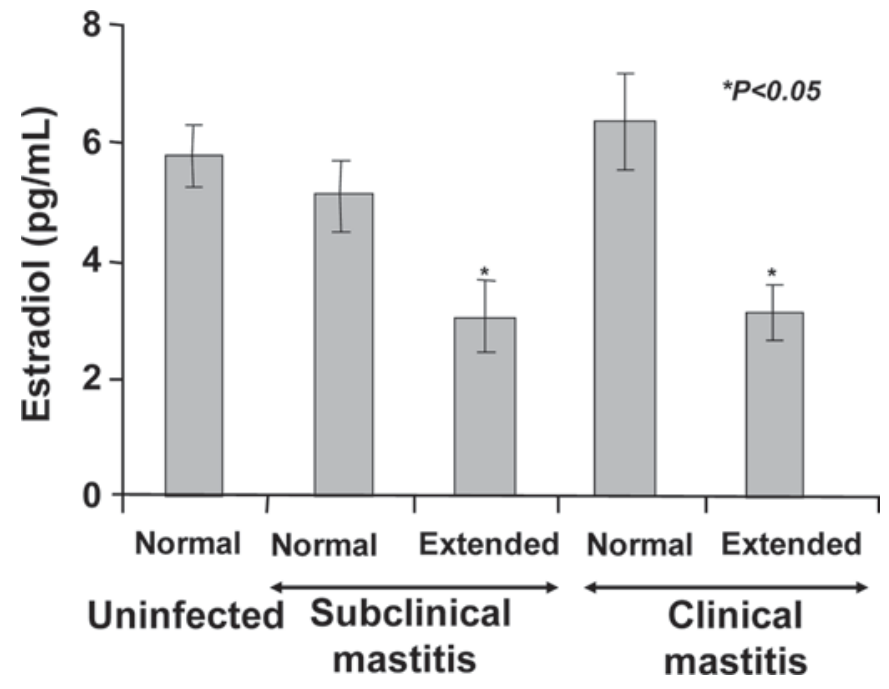

Figure 3. Mean $( \pm \mathrm{SE})$ concentrations of estradiol in plasma at onset of estrus in uninfected cows $(\mathrm{n}=11)$ exhibiting a normal estrus to ovulation (E-O) interval and in subclinical or clinical mastitic cows exhibiting normal ( $\mathrm{n}=14$ or 6 , respectively) or extended $(\mathrm{n}=6$ or 2, respectively) E-O intervals. An asterisk indicates the difference between uninfected, clinical mastitic, and subclinical mastitic cows exhibiting a normal E-O interval and subclinical and clinical cows exhibiting an extended E-O interval $(P<0.05)$.

of the dominant follicle during the second follicular wave (d 16-20) was larger in uninfected and in subclinical cows with a normal interval compared with subclinical cows with an extended interval $(13.4 \pm 0.5$ and 13.5 \pm 0.4 vs. $10.9 \pm 0.9 \mathrm{~mm}$ in diameter, respectively; $P$ $<0.05$; Figure 7). Clinical normal cows did not differ among groups $(11.8 \pm 0.9 \mathrm{~mm})$. The number of medium follicles (5-9 $\mathrm{mm}$ in diameter) was higher in subclinical cows with an extended E-O interval than in the other groups of cows with a normal E-O interval $(P$ $<0.05$; Figure 8a). On d 4 (first wave) and 16 (second wave) of the cycle, subclinical cows with an extended E-O interval had $6.7 \pm 0.14$ follicles compared with 3.8 \pm 0.2 follicles in the other sets $(P<0.05)$. The number of large follicles during the cycle did not differ among groups (Figure 8b).

\section{DISCUSSION}

This study investigated the disruptive effects of naturally occurring clinical or subclinical mastitis on reproductive processes and their association with an extended E-O interval of the preovulatory follicle. The reproductive responses of $70 \%$ of the mastitic cows were unaltered; however, about $30 \%$ of mastitic cows exhibited delayed ovulation. The extension of the normal E-O interval from 30 to $60 \mathrm{~h}$, shown here for the first time, significantly minimizes the probability of successful fertilization of those cows inseminated following estrus because of the short fertile life of spermatozoa in the female tract and of the oocytes after ovulation.

Delayed ovulation in $30 \%$ of mastitic cows provided a possible explanation for the negative effects of mastitis, occurring before AI regarding the conception rate, which was documented in epidemiological studies (Schrick et al., 2001; Santos et al., 2004). The current study indicated that naturally occurring mastitis-induction of delayed ovulation was initiated primarily from direct depression of estradiol production, resulting in reduced preovulatory estradiol concentrations. Consequently, it suggested that the stimulatory effect of estradiol on GnRH induction of LH surge secretion was probably depressed. This led to low or delayed or no LH surge in about $30 \%$ of mastitic cows, which subsequently resulted in delayed ovulation. The direct disruptive effect of mastitis on estradiol production probably does not involve alterations in gonadotropin secretion because we did not detect depressive effects of mastitis, neither clinical nor subclinical, on pulsatile secretion of $\mathrm{LH}$ (Table 2). With regard to the above, we recently found a similar proportion of subclinical mastitic cows that manifested impaired preovulatory follicular responses. A low follicular fluid estradiol level was associated with a low androstenedione level and with low expression of steroidogenic genes in granulosa cells in one-third of cows (Lavon et al., 2008b, 2009a).

In agreement with the above, mastitis did not affect cortisol concentrations. This finding is important because, in contrast with subclinical mastitis or clinical events that ended earlier, acute mastitis-induced secretion of inflammatory mediators increased the release of hypothalamic corticotrophin-releasing hormone, which activated the adrenal axis. The latter inhibited pulsatile LH secretion in several species, including cattle (Battaglia et al., 2000; Dobson and Smith, 2000). Direct suppression of follicular estradiol as a primary effect of subclinical mastitis, or clinical mastitis that ended with no suppression of pulsatile LH, differs substantially from several studies performed in cattle (Hockett et al., 2005; Lavon et al., 2008a). In these studies, the immediate disruptive acute phase effect of endotoxin or bacterial inoculation on reproduction involved primarily a depression of gonadotropin secretion. Attenuating pulsatile LH secretion during the follicular phase resulted in low preovulatory estradiol concentrations and low LH surge that blocked or delayed ovulation.

A possible direct effect of mastitis on attenuation of estradiol secretion is supported by the finding that cytokines such as TNF $\alpha$ and IL-1 $\beta$ inhibit steroidogenesis (Sakumoto et al., 2003). Addition of TNFa to bovine granulosa or theca cell cultures lowered steroid production (Spicer, 1998). Yet, cytokine secretion to the circulation during subclinical mastitis has not been 
Table 2. Pulsatile LH concentrations (mean, pulses per $6 \mathrm{~h}$, and amplitude) in uninfected $(\mathrm{n}=5)$, subclinical $(\mathrm{n}=6)$, and clinical mastitic $(\mathrm{n}=5)$ cows $^{1}$

\begin{tabular}{lccc}
\hline Item & Mean $(\mathrm{ng} / \mathrm{mL})$ & Pulses $/ 6 \mathrm{~h}$ & Amplitude $(\mathrm{ng} / \mathrm{mL})$ \\
\hline Uninfected & $1.3 \pm 0.1$ & $5.0 \pm 0.7$ & $0.8 \pm 0.1$ \\
Subclinical & $1.2 \pm 0.1$ & $6.3 \pm 0.3$ & $0.7 \pm 0.1$ \\
Clinical & $1.4 \pm 0.3$ & $5.2 \pm 0.4$ & $0.7 \pm 0.1$ \\
\hline
\end{tabular}

${ }^{1}$ Samples were taken during the follicular phase, $36 \mathrm{~h}$ after $\mathrm{PGF}_{2 \alpha}$.

examined to date, to the best of our knowledge. The exact mechanism responsible for induction of low secretion of estradiol in cows with clinical events that ended weeks earlier, or in cases of subclinical mastitis, is unclear and remains to be elucidated.

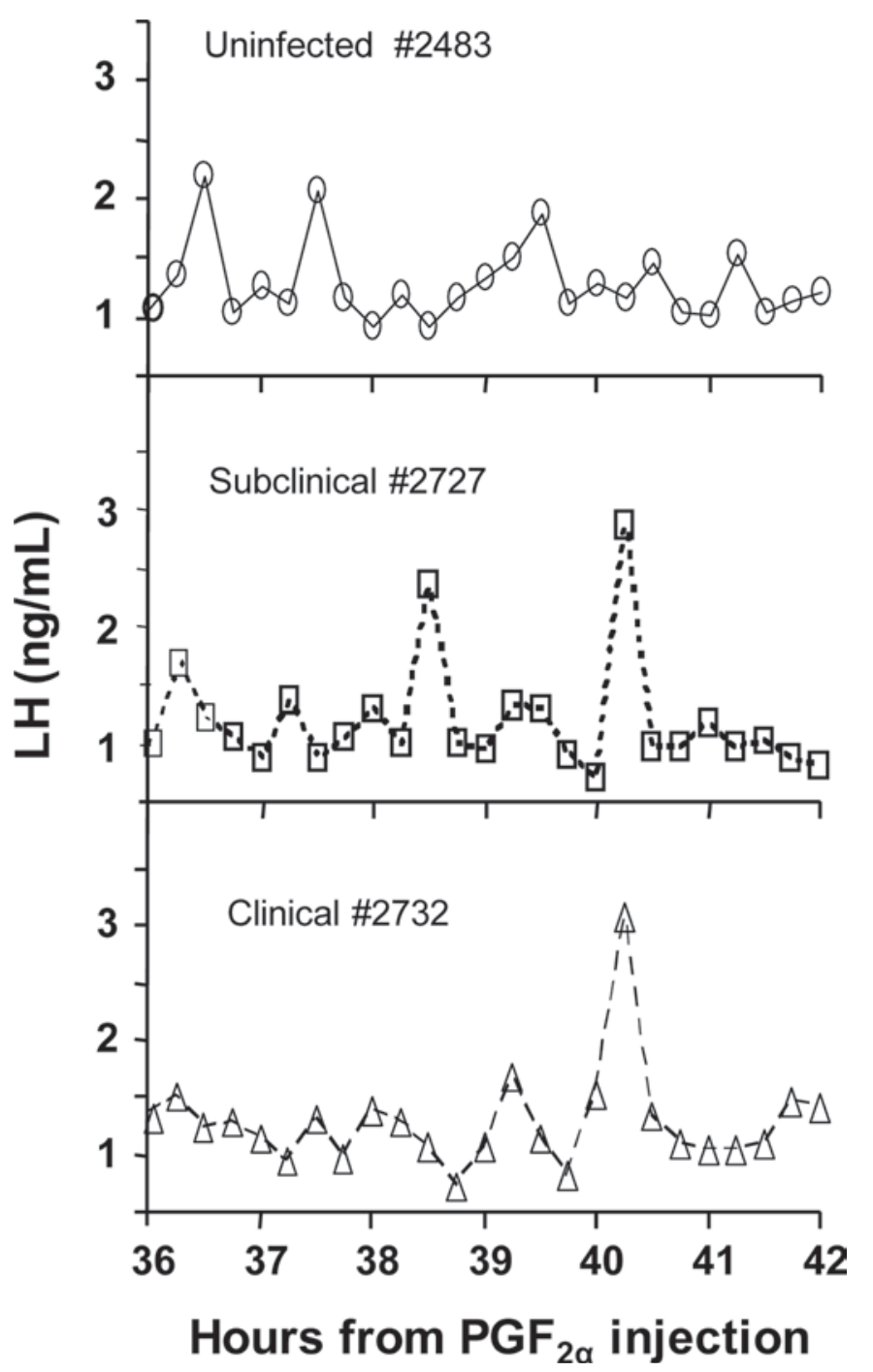

Figure 4. Pulsatile LH concentrations in representative uninfected, subclinical mastitic, and clinical mastitic cows. Samples were taken in the follicular phase over $6 \mathrm{~h}$ at 15-min intervals.
Although the findings presented associated with long-term subclinical mastitis on the preovulatory follicle are much more established and sound than those associated with clinical events that ended several weeks earlier, we chose to present both. Presentation of the responses of the smaller subgroup of clinical mastitic cows is noteworthy because it induced changes in reproductive responses that were similar to those induced by subclinical mastitis. They may explain the carryover effect of clinical cases, before AI, on low conception rates. Clinical events that ended $20 \pm 7 \mathrm{~d}$ before the preovulatory/ovulatory period had a long-term effect on reproductive responses. About $20 \%$ of the cows with a history of clinical mastitis had an extended E-O interval. However, these findings should be treated with caution because of their lack of statistical significance, which could be related to the small sample size. One can assume that a clinical mastitis event impairs, during the acute phase, some functions of small follicles during early stages of folliculogenesis, and that this disruptive effect is expressed later, during the preovulatory stage. Interestingly, a similar delayed effect of acute, shortterm heat stress causing depression of steroidogenesis in large dominant follicles $4 \mathrm{wk}$ later showed impaired function of small follicles during the early stages (Roth et al., 2001). It is worth mentioning that the subclinical mastitis appears more pronounced and effective in inducing disruption of preovulatory follicular function in about $30 \%$ of the infected cows.

Interestingly, all cows that exhibited delayed ovulation manifested before it standing estrous behavior. Another important point is that mastitis induction of cysts was not evident in all cows (except 1). Even among the 4 cows that did not ovulate during the $96 \mathrm{~h}$ after onset of estrus, a turnover of follicular dominance was eventually noted in all, including the 1 cow that had a cyst. On this limited basis, it can be concluded that subclinical mastitis or clinical events that ended did not induce cysts.

The diversity between individual mastitic cows in terms of exhibiting a normal or an extended E-O interval is unclear. Also unclear is the high variability in the pattern of the preovulatory LH surge, whether low and delayed, or normal and delayed, or when no surge was evident among the cows with an extended E-O 
(a)
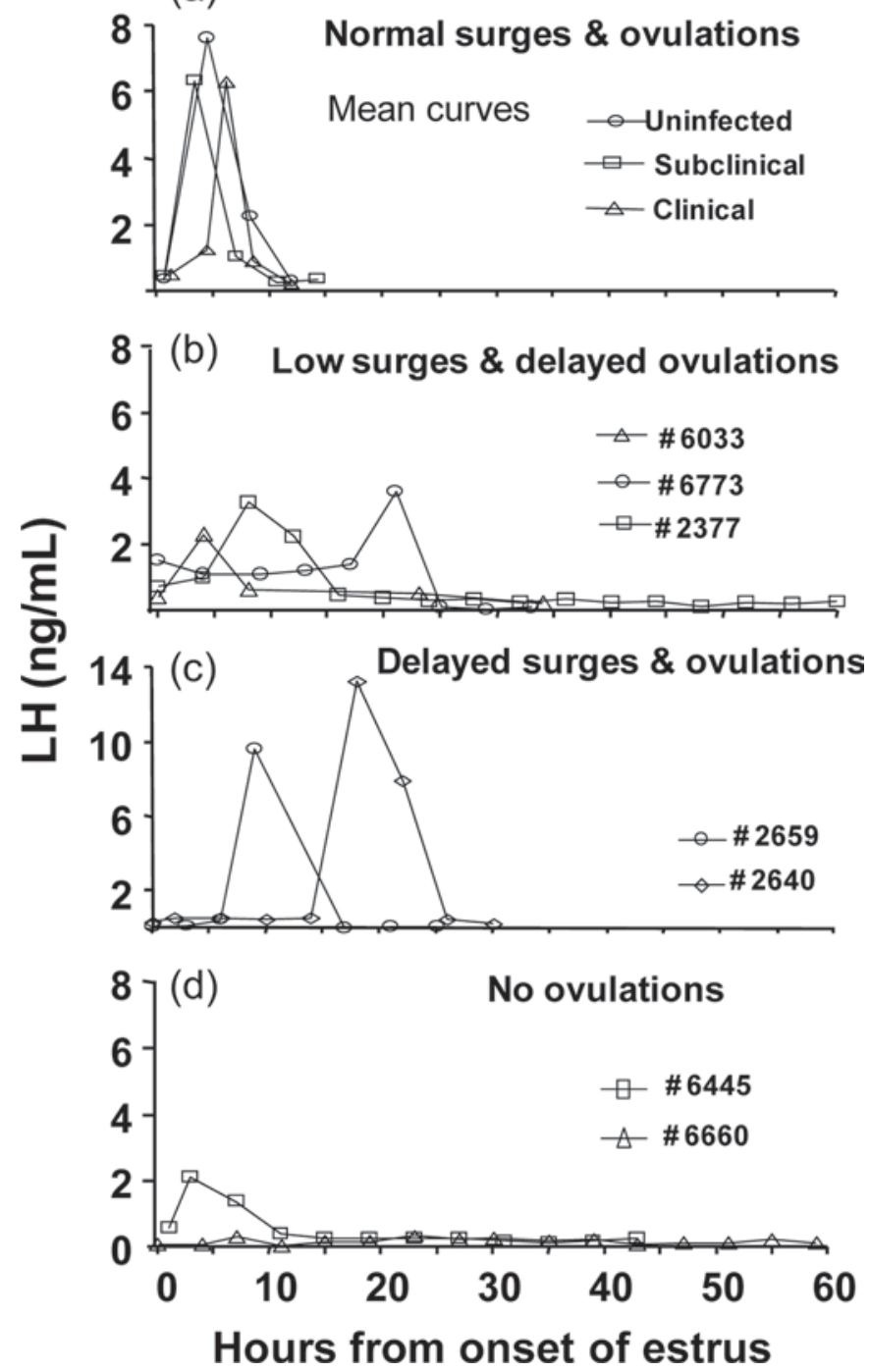

Figure 5. Concentrations of LH in plasma around the preovulatory surge. a) Means of uninfected $(\mathrm{n}=10)$, subclinical mastitic ( $\mathrm{n}$ $=10)$, or clinical mastitic $(n=5)$ cows exhibiting a normal estrus to ovulation interval. Pooled SEM are 1.1, 1.8, and $1.6 \mathrm{ng} / \mathrm{mL}$, respectively. b) Individual LH concentrations of 3 mastitic cows exhibiting low LH surges, which subsequently manifested delayed ovulation. c) Individual LH concentrations of 2 mastitic cows exhibiting normal but delayed LH surges, which subsequently manifested delayed ovulation. d) Individual LH concentrations of 2 mastitic cows that did not exhibit or exhibited a minimal LH surge and subsequently did not ovulate during the $96-\mathrm{h}$ experimental period.

interval. Moreover, the occurrence of delayed ovulation in individual mastitic cows could not be related to the level of milk yield, BCS, stage and number of lactations, bacterial type, level of SCC, and postpartum uterine diseases. Nevertheless, the 70:30 proportion of subclinical mastitic cows exhibiting normal or extended E-O intervals and associated alterations in hormonal concentrations were evident in 2 studies with naturally
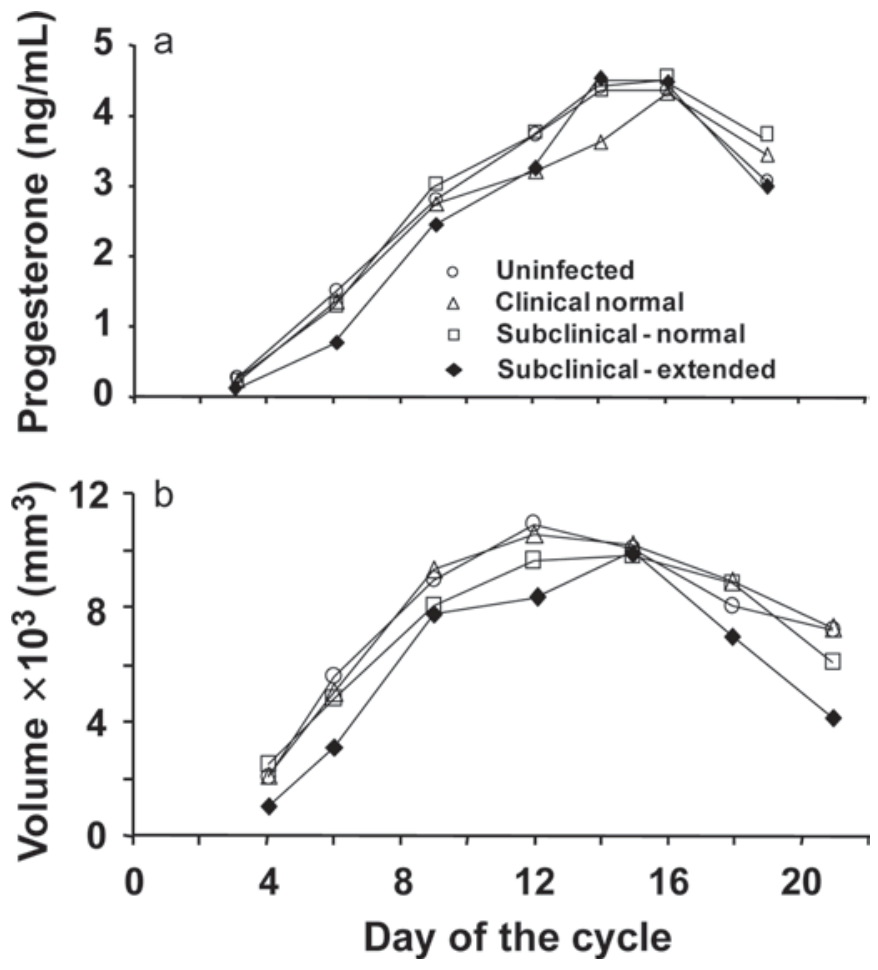

Figure 6. a) Mean concentrations of progesterone in plasma of uninfected cows $(\mathrm{n}=14)$, cows with clinical mastitis $(\mathrm{n}=7)$, and cows with subclinical mastitis $(\mathrm{n}=27)$ exhibiting a normal estrus to ovulation (E-O) interval, and cows with subclinical mastitis $(\mathrm{n}=5)$ exhibiting an extended E-O interval. Data from 1 uninfected cow and 1 clinical mastitic cow, which had exhibited an extended E-O interval, are not shown. Pooled SEM are 0.19, 0.3, 0.13, and $0.37 \mathrm{ng} / \mathrm{mL}$, respectively. b) Mean volume of the corpus luteum in uninfected cows (n $=18)$, cows with clinical mastitis $(\mathrm{n}=7)$, and cows with subclinical mastitis $(\mathrm{n}=32)$ exhibiting a normal E-O interval, and cows with subclinical mastitis $(\mathrm{n}=6)$ exhibiting an extended E-O interval. Pooled SEM are 524, 841, 393, and $447 \mathrm{~mm}^{3}$, respectively. Progesterone in plasma and the corpus luteum volume did not differ among groups, and there were no interactions between group and day.

occurring mastitis (Lavon et al., 2008b, Lavon et al., 2009a). Our data support Burvenich et al. (2003), who stated that the severity of naturally occurring cases of clinical and subclinical mastitis and the variability in responses among individuals was largely related to cow factors. Accordingly, it is not clear what cow factors caused one-third of the infected cows to be susceptible to mastitis.

The slight numerical delay in rise in progesterone concentrations and CL growth after ovulation may be associated with delayed ovulation in the subclinical cows with an extended E-O interval $(\mathrm{n}=5)$. Studies indicated an association between a delayed rise in progesterone during the first days following AI and reduced embryo development and low conception rates (Robinson et al., 2006). In contrast, a study performed in nonlactating Holsteins (Starbuck et al., 2006) claimed 


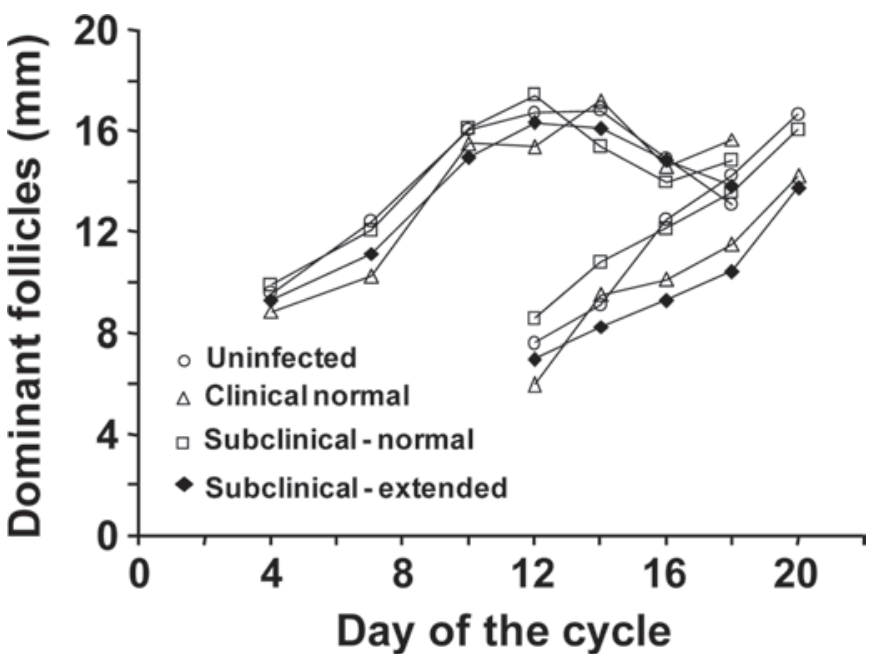

Figure 7. Growth patterns of the first- and second-wave dominant follicles during the estrus cycle following ovulation of uninfected ( $\mathrm{n}=$ $17)$, clinical mastitic $(\mathrm{n}=7)$, and subclinical mastitic $(\mathrm{n}=32)$ cows exhibiting a normal estrus to ovulation (E-O) interval, and subclinical mastitic cows $(n=6)$ exhibiting an extended E-O interval. Pooled SEM for the respective groups during the first follicular wave were 0.6 , $0.8,0.3$, and $0.8 \mathrm{~mm}$, and during the second follicular wave were 0.5 , $1.0,0.4$, and $0.9 \mathrm{~mm}$. The second-wave dominant follicle (d 14-20) was smaller in subclinical cows with an extended E-O interval compared with uninfected and subclinical-normal groups $(P<0.05)$.

that the delayed rise in progesterone was not a result of delayed ovulation but rather of suboptimal luteal functioning.

Alterations in follicular growth dynamics following estrus and ovulation in subclinical cows with an extended E-O interval corresponded well to the delayed ovulation in that group of cows. The higher number of medium follicles and the low number of large follicles on d 4 of the cycle in cows exhibiting delayed ovulation probably resulted from late gain of dominance of the first-wave dominant follicle. A similarly higher number of medium follicles, noted on d 16 of the cycle, could be related to weak dominance of the second-wave dominant follicle in the delayed-ovulation cows.

In conclusion, the results indicated that subclinical, long-term mastitis and short-term clinical events that ended earlier induced delayed ovulation in about $30 \%$ of the cows. This syndrome was primarily associated with low estradiol concentrations that subsequently induced low or delayed or no LH surge, without any change in pulsatile LH secretion, suggesting that mastitis directly affected follicular functioning. The variability among mastitic cows regarding their reproductive responses being unaltered or depressed is unclear and needs further investigation. The findings could explain, in part, the disruptive effect of mastitis, before AI, on low fertility in dairy cows.
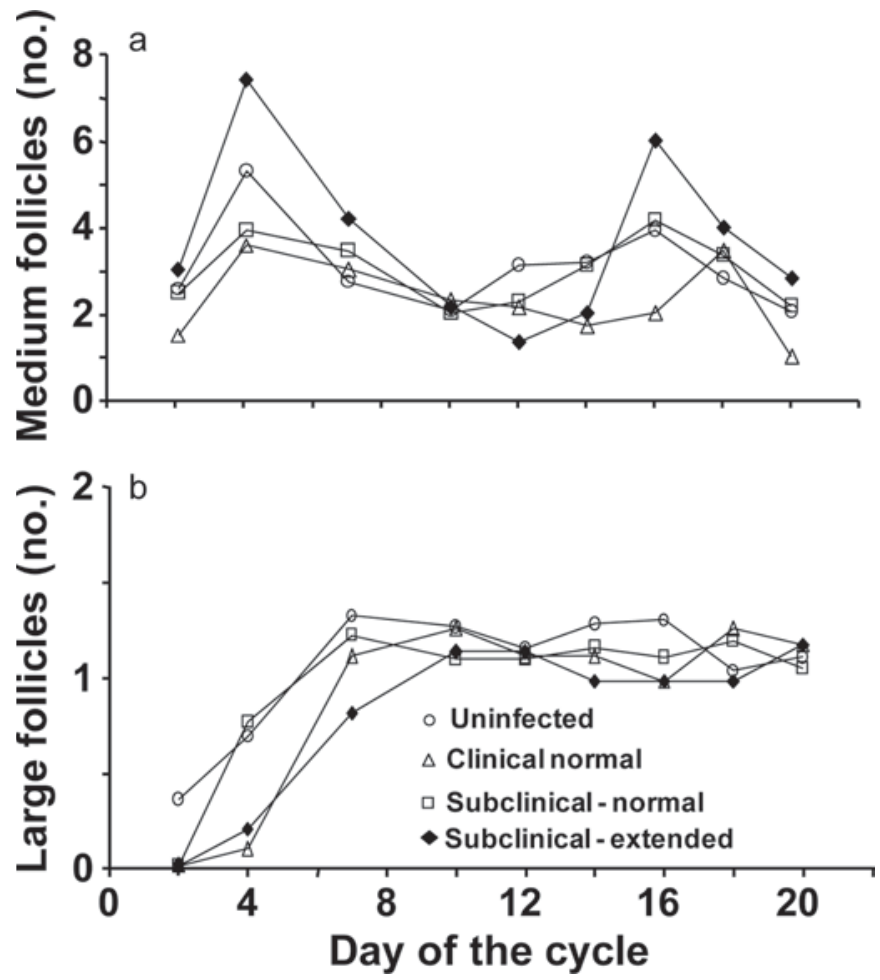

Figure 8. Numbers of a) medium follicles (5-9 mm) and b) large follicles $(>10 \mathrm{~mm})$ of uninfected $(\mathrm{n}=17)$, clinical mastitic $(\mathrm{n}=7)$, and subclinical mastitic $(\mathrm{n}=32)$ cows exhibiting a normal estrus to ovulation (E-O) interval, and subclinical mastitic cows $(\mathrm{n}=6)$ exhibiting an extended E-O interval. Pooled SEM for the respective groups for the number of medium follicles were $0.25,0.21,0.19$, and 0.46 and for large follicles were $0.08,0.09,0.07$, and 0.17 , respectively. The number of medium follicles was greater in subclinical cows with an extended E-O interval compared with the other groups $(P<0.05)$. The number of large follicles did not differ among groups, and there was no interaction of group by day.

\section{ACKNOWLEDGMENTS}

The authors thank G. Glick (Faculty of Agriculture, Rehovot, Israel), O. Krifucks and L. Weisblit (Veterinary Institute, Bet-Dagan, Israel) for their valuable help, and S. Jacoby (experimental dairy herd in BetDagan) for his cooperation in performing this study.

\section{REFERENCES}

Battaglia, D. F., H. B. Krasa, V. Padmanabhan, C. Viguie, and F. J. Karsch. 2000. Endocrine alterations that underlie endotoxininduced disruption of the follicular phase in ewes. Biol. Reprod. 62:45-53.

Bloch, A., Y. Folman, M. Kaim, Z. Roth, R. Braw-Tal, and D. Wolfenson. 2006. Endocrine alterations associated with extended time interval between estrus and ovulation in high-yield dairy cows. J. Dairy Sci. 89:4694-4702.

Burvenich, C., V. Van Merris, J. Mehrzad, A. Diez-Fraile, and L. Duchateau. 2003. Severity of E. coli mastitis is mainly determined by cow factors. Vet. Res. 34:521-564. 
Dobson, H., and R. F. Smith. 2000. What is stress, and how does it affect reproduction? Anim. Reprod. Sci. 60-61:743-752.

Giri, S. N., G. H. Stabenfeldt, T. A. Moseley, T. W. Graham, M. L. Bruss, R. H. BonDurant, J. S. Cullor, and B. I. Osburn. 1991. Role of eicosanoids in abortion and its prevention by treatment with flunixin meglumine in cows during the first trimester of pregnancy. J. Vet. Med. A 38:445-459.

Heringstad, B., Y. M. Chang, I. M. Andersen-Ranberg, and D. Gianola. 2006. Genetic analysis of number of mastitis cases and number of services to conception using a censored threshold model. J. Dairy Sci. 89:4042-4048.

Hockett, M. E., R. A. Almeida, N. R. Rohrbach, S. P. Oliver, H. H. Dowlen, and F. N. Schrick. 2005. Effects of induced clinical mastitis during preovulation on endocrine and follicular function. J. Dairy Sci. 88:2422-2431.

Hockett, M. E., F. M. Hopkins, M. J. Lewis, A. M. Saxton, H. H. Dowlen, S. P. Oliver, and F. N. Schrick. 2000. Endocrine profiles of dairy cows following experimentally induced clinical mastitis during early lactation. Anim. Reprod. Sci. 58:241-251.

Huszenicza, G., S. Janosi, M. Kulcsar, P. Korodi, J. Reiczigel, L. Katai, A. R. Peters, and F. De Rensis. 2005. Effects of clinical mastitis on ovarian function in post-partum dairy cows. Reprod. Domest. Anim. 40:199-204.

Klaas, I. C., U. Wessels, H. Rothfuss, B. A. Tenhagen, W. Heuwieser, and E. Schallenberger. 2004. Factors affecting reproductive performance in German Holstein-Friesian cows with a special focus on postpartum mastitis. Livest. Prod. Sci. 86:233-238.

Konig, S., G. Hubner, R. Sharifi, E. Bohlsen, J. Detterer, H. Simianer, and W. Holtz. 2006. Relation between the somatic cell count and the success of first insemination in East Frisian dairy herds on the basis of logistic models analysis. Zuchtungskunde 78:90-101.

Lavon, Y., G. Leitner, T. Goshen, R. Braw-Tal, S. Jacoby, and D. Wolfenson. 2008a. Exposure to endotoxin during estrus alters the timing of ovulation and hormonal concentrations in cows. Theriogenology 70:956-967.

Lavon, Y., G. Leitner, R. Meidan, E. Klipper, and D. Wolfenson. 2009a. Subclinical mastitis effects on steroid concentrations and gene expression in theca cells of preovulatory follicles in cows. J. Dairy Sci. 92(Suppl. 1):444. (Abstr.)

Lavon, Y., G. Leitner, R. Meidan, U. Moallem, E. Klipper, and D. Wolfenson. 2008b. Subclinical mastitis lowers steroid concentrations and gene expression in preovulatory follicles of lactating cows. Reprod. Domest. Anim. 43:207. (Abstr.)

Lavon, Y., G. Leitner, R. Meidan, U. Moallem, E. Klipper, and D. Wolfenson. 2009b. Immediate and carryover effects of Gramnegative or Gram-positive toxin-induced mastitis on follicular functions in cows. J. Dairy Sci. 92(Suppl. 1):442. (Abstr.)

Miller, R. H., J. S. Clay, and H. D. Norman. 2001. Relationship of somatic cell score with fertility measures. J. Dairy Sci. 84:25432548.

Oliver, S. P., R. A. Almeida, B. E. Gillespie, S. J. Headrick, H. H. Dowlen, D. L. Johnson, K. C. Lamar, S. T. Chester, and W.
M. Moseley. 2004. Extended ceftiofur therapy for treatment of experimentally-induced Streptococcus uberis mastitis in lactating dairy cattle. J. Dairy Sci. 87:3322-3329.

Robinson, R. S., A. J. Hammond, L. T. Nicklin, D. Schams, G. E. Mann, and M. G. Hunter. 2006. Endocrine and cellular characteristics of corpora lutea from cows with a delayed post-ovulatory progesterone rise. Domest. Anim. Endocrinol. 31:154-172.

Roelofs, J. B., F. J. C. M. van Eerdenburg, N. M. Soede, and B. Kemp. 2005. Various behavioral signs of estrous and their relationship with time of ovulation in dairy cattle. Theriogenology 63:13661377.

Roth, Z., R. Meidan, A. Shaham-Albalancy, R. Braw-Tal, and D. Wolfenson. 2001. Delayed effect of heat stress on steroid production in medium-sized and preovulatory bovine follicles. Reproduction 121:745-751.

Sakumoto, R., M. Shibaya, and K. Okuda. 2003. Tumor necrosis factoralpha (TNF alpha) inhibits progesterone and estradiol-17beta production from cultured granulosa cells: Presence of TNFalpha receptors in bovine granulosa and theca cells. J. Reprod. Dev. 49:441-449.

Santos, J. E., R. L. Cerri, M. A. Ballou, G. E. Higginbotham, and J. H. Kirk. 2004. Effect of timing of first clinical mastitis occurrence on lactational and reproductive performance of Holstein dairy cows. Anim. Reprod. Sci. 80:31-45.

Schrick, F. N., M. E. Hockett, A. M. Saxton, M. J. Lewis, H. H Dowlen, and S. P. Oliver. 2001. Influence of subclinical mastitis during early lactation on reproductive parameters. J. Dairy Sci. 84:1407-1412.

Shaham-Albalancy, A., M. Rosenberg, Y. Folman, Y. Graber, R. Meidan, and D. Wolfenson. 2000. Two methods of inducing low plasma progesterone concentrations have different effects on dominant follicles in cows. J. Dairy Sci. 83:2771-2778.

Spicer, L. J. 1998. Tumor necrosis factor-alpha (TNF-alpha) inhibits steroidogenesis of bovine ovarian granulosa and thecal cells in vitro. Involvement of TNF-alpha receptors. Endocrine 8:109-115.

Starbuck, G. R. C. G. Gutierrez, A. R. Peters, and G. E. Mann. 2006. Timing of follicular phase events and the postovulatory progesterone rise following synchronization of oestrus in cows. Vet. J. 172:103-108.

Turzillo, A. M., and J. E. Fortune. 1990. Suppression of the secondary FSH surge with bovine follicular fluid is associated with delayed ovarian follicular development in heifers. J. Reprod. Fertil. 89:643-653.

Veldhuis, J. D., and M. L. Johnson. 1986. Cluster analysis: A simple, versatile, and robust algorithm for endocrine pulse detection. Am. J. Physiol. Endocrinol. Metab. 250:E486-E493.

Younis, A., O. Krifucks, E. D. Heller, Z. Samra, A. Glickman, A. Saran, and G. Leitner. 2003. Staphylococcus aureus exosecretions and bovine mastitis. J. Vet. Med. B. 50:1-7. 